\title{
Towards a Tolerance of Ambiguity Model in Greek Tourism Industry
}

\author{
Kleanthis K. Katsaros, Athanasios N. Tsirikas, Sofia-Maria N. Bani, Christos S. Nicolaidis \\ University of Macedonia, Thessaloniki, Greece
}

\begin{abstract}
The present paper examines the influence of locus of control, involvement, job satisfaction, and organizational commitment on hotel chief executive officers' (CEOs) tolerance of ambiguity. The research sample consists of 82 Greek hotels' CEOs. The first part of this paper analyses their level of locus of control, involvement, job satisfaction, and organizational commitment, in front of the frequent, uncertain, and ambiguous changes in their business environment. In the second part, results of principal component analysis indicate that two factors characterize CEOs' involvement, namely, importance and interest. Further, regression results reveal the significant influence of interest, locus of control, and job satisfaction on CEOs' tolerance of ambiguity. Finally, this paper discusses the research findings and proposes certain practical implications for enhancing Greek hotel CEOs' level of tolerance of ambiguity and thus, their efficiency during change.
\end{abstract}

Keywords: ambiguity, chief executive officers (CEOs), change, emotional behavior

\section{Introduction}

Current constant political, economic, social, and technological changes have established a unique business environment. Thus, nowadays, organizational members' success highly depends on the extent to which they are able to cope with change ambiguity/uncertainty in their business environment (Nicolaidis \& Katsaros, 2011). In this respect, the main aim of this paper is to examine the influence of certain significant perceptual and attitudinal factors on chief executive officers' (CEOs) tolerance of ambiguity. We chose CEOs due to their key roles in an environment where the complexity and the pace of change increase (Johnson \& Scholes, 2002) and tourism industry, as a rapidly growing sector with extremely high change rates in terms of novelty, competition, development, and growth in Greece (Armenakis, Harris, \& Mossholder, 1993).

The first part of this paper makes a brief reference to the relevant literature as well as to the background of the research. The second part of this paper, via a statistical analysis, examines CEOs': (1) level of ambiguity tolerance; (2) locus of control; (3) involvement during changes in their business environment; (4) degree of job satisfaction; and (5) organizational commitment. Further, it investigates the relationship between CEOs' tolerance of ambiguity and the above mentioned factors. The final part of this paper discusses the results and proposes a number of certain policies that may effectively influence CEOs' performance towards change.

Kleanthis K. Katsaros, adjunct lecturer, Accounting \& Finance, University of Macedonia. Email: kleanthis.katsaros@gmail.com.

Athanasios N. Tsirikas, adjunct lecturer, Accounting \& Finance, University of Macedonia.

Sofia-Maria N. Bani, research associate, Accounting \& Finance, University of Macedonia.

Christos S. Nicolaidis, professor, Accounting \& Finance, University of Macedonia. 


\section{Tolerance of Ambiguity}

Tolerance of ambiguity, among others, is defined as one's acceptance of confusing situations and lack of clear lines of differentiation (Ely, 1989). It refers to the way a particular individual perceives stimuli and processes information. An individual with a low tolerance of ambiguity experiences stress, avoids ambiguity, and seeks for certainty. On the contrary, an individual with a high tolerance of ambiguity perceives ambiguous situations as desirable, interesting, attractive, and hence, approaches problems from innovative perspectives (Kirton, 1981).

Numerous attempts have been made to examine the relationship between tolerance of ambiguity and several personal, emotional, behavioral, and working attitudes. Generally, individuals with a high tolerance of ambiguity can better cope with unstructured and dynamic situations characterized by uncertainty and ambiguity (Budner, 1962). As a consequence, tolerance of ambiguity is correlated with: creativity (Tegano, 1990), decision-making and critical thinking (Wilkinson, 2006), risk acceptance (Lauriola \& Levin, 2001), and effective performance in new situations (Jonassen \& Grabowski, 1993).

\section{Perceptions and Attitudes}

On the whole, our workplace behavior is significantly influenced by our perceptions, personality traits, attitudes, and experiences (Langton \& Robbins, 2006).

Locus of control refers to an individual's perception about whether the upcoming evolutions depend on what he/she does (internal orientation) or on events outside his/her personal control (external orientation) (Zimbardo, 1985). Begley and Boyd (1987) suggested that an internal locus of control may relate to higher performance, but at excessive levels can result in a decline of performance. That is, excessive belief in the personal efficacy produces careless behaviors, which may ignore emerging external dangers. On the other hand, people with an external locus of control tend to be more stressed and anxious (Benassi, Sweeney, \& Dufour, 1988) and unwilling to take risks and work on self-improvement (Rotter, 1975). On the whole, the international literature suggests that generally managers appear to be more internals (Mamlin, Harris, \& Case, 2001).

Involvement is mainly defined as an employee's willingness to support the organization even if it requires additional time and effort (Madsen, Miller, \& Cameron, 2005). The literature suggests that employees' involvement relates to their cognitive support during the change process and may promote personal and organizational readiness for change (Armenakis et al., 1993). Scholars suggest that involvement can be examined along a number of dipolar dimensions that can be viewed as independent of each other. Respectively, McQuarrie and Munson (1991) supported that involvement can be examined by two bipolar dimensions, namely, importance and interest. Importance refers to the perceived importance of an event and/or to the quality of being important; and interest concerns the personal interest that a person has in an event.

Job satisfaction is mainly defined as the emotional and cognitive attitude held by an employee about different aspects of his/her work (Wong, Hui, \& Law, 1998). It may simultaneously influence and be influenced by organizational changes and environmental ambiguity. For instance, Schweiger and DeNisi (1991) found that employees involved in a merger exhibited decreased levels of job satisfaction, while Wanberg and Banas (2000) found that low levels of change acceptance were associated with decreased job satisfaction. More to the point, research has identified a positive relationship between job satisfaction and ambiguity tolerance and it suggests that job satisfaction plays a critical role in employees' acceptance of change (Judge, Thoreson, Pucik, \& Welbourne, 1999; Nicolaidis \& Katsaros, 2011). 
Organizational commitment is defined as the relative strength of an individual's identification with and involvement in a particular organization (Mowday, Steers, \& Porter, 1979). There is evidence in the change management literature that organizational commitment plays an important role in employee's acceptance of change ambiguity/uncertainty. Relatively, Lau and Woodman (1995) argued that a highly committed employee is more willing to accept an organizational change if it is perceived to be useful. That is, an individual committed to an organization accepts its values, is willing to exert effort on its behalf, and wishes to remain in the organization (Mowday et al., 1979). However, they noted that a highly committed employee may resist to change if he/she perceives it as a threat for his/her own benefit or harmful to the organization.

On the whole, managers' tolerance of ambiguity seems to be affected by their locus of control, involvement, job satisfaction, and organizational commitment. Therefore, it emerges the main hypothesis of this paper:

H1: The interaction of managers' locus of control, job satisfaction, organizational commitment, and involvement affects their ambiguity tolerance.

\section{Research Background}

Greek tourism plays a vital role in the Greek economy. It is ranked worldwide 21st in absolute size and 37th in its relative contribution to national economies. In more detail, it accounts nationally for about $15.5 \%$ of the gross domestic product (GDP) (EUR33.9 bn or US $\$ 50.2 \mathrm{bn}$ ), $18.8 \%$ of total employment $(785,000$ jobs or 1 in every 5.3), and $14.2 \%$ of total investment. Further, Greece is consistently ranked in the top 15 destinations for global travelers with more than 15 million tourists per year.

Though, a climate of uncertainty and insecurity is prevailing in the Greek tourism industry as a result of the severe national economic crisis. Greece is required to slash spending and restructure large parts of its economy, in exchange for the 110 billion euro rescue plan funded by the International Monetary Fund, the European Union, and the European Central Bank. As a consequence, there are continuous strikes, rallies, work stoppages, protests, and social conflicts that may harm Greece's image and have negative consequences to the tourism development. Relevantly, the Association of Greek Tourism Enterprises along with the Hellenic Chamber of Hotels forecasted that in 2010, tourist arrivals might fall more than $20 \%$ and thus, might provoke massive lay-offs particularly in hotels (about 50,000 new unemployed). In any case, it should be noted that the current and forthcoming changes may cause severe ambiguity/uncertainty and thus, affect negatively Greek hotel CEOs' overall performance.

\section{Research}

Taking into account the importance of the tourism industry to the Greek economy, the current complexities that provoke intense changes, and the total absence of relevant researches in Greece, the purpose of this research was, firstly, to examine CEOs' locus of control, involvement, job satisfaction, and organizational commitment, and secondly, to investigate the influence of the above mentioned factors on their level of tolerance of change ambiguity.

This research was conducted during a 7-month period in 2010. Survey data were collected from hotels established in Greece. In the first two months, a pilot test was conducted in order to examine the functionality of this research. Subsequently, the structured questionnaires were personally delivered to the CEOs by the research team. Overall, 82 Greek hotels' CEOs participated in this research (a response rate of 38.8\%). Tables 1 and 2 summarize the demographic characteristics of the participants in our research. 
Table 1

Demographic Characteristics of the Sample by CEOs

\begin{tabular}{llrc}
\hline \multirow{2}{*}{ Variable } & & \multicolumn{2}{c}{ CEO } \\
\cline { 3 - 4 } Sex & Male & \multicolumn{1}{c}{ Frequency (\%) } \\
\hline \multirow{2}{*}{ Age } & Female & 5 & 78.05 \\
& $25-34$ years & 26 & 21.95 \\
\hline \multirow{2}{*}{ Marital status } & 35-44 years & 51 & 6.10 \\
& M5+ years & 66 & 31.71 \\
\multirow{2}{*}{ Education } & Single & 16 & 62.19 \\
\hline \multirow{2}{*}{ Working experience } & Secondary & 29 & 80.49 \\
(pr. position) & University & 39 & 19.51 \\
\hline Total working & Master/Ph.D. & 14 & 35.37 \\
experience & $11+5-10$ & 35 & 47.56 \\
\hline
\end{tabular}

Table 2

Demographic Characteristics of the Sample by Hotels

\begin{tabular}{|c|c|c|c|}
\hline \multirow{2}{*}{ Variable } & & \multicolumn{2}{|c|}{ Hotel } \\
\hline & & $N$ & Frequency (\%) \\
\hline \multirow{4}{*}{ Age } & $1-5$ years & 8 & 9.76 \\
\hline & $6-10$ years & 26 & 31.71 \\
\hline & $11-15$ years & 31 & 37.80 \\
\hline & $16+$ years & 17 & 20.73 \\
\hline \multirow{4}{*}{ Number of employees } & $1-10$ & 9 & 10.98 \\
\hline & $11-50$ & 39 & 47.56 \\
\hline & $51-250$ & 26 & 31.70 \\
\hline & $251+$ & 8 & 9.76 \\
\hline \multirow{3}{*}{ Firm life circle } & Initial & 11 & 13.41 \\
\hline & Growth & 49 & 59.76 \\
\hline & Mature & 22 & 26.83 \\
\hline \multirow{4}{*}{ Annual turnover } & $<1$ million & 8 & 9.76 \\
\hline & 1-10 million & 45 & 54.87 \\
\hline & 11-100 million & 21 & 25.61 \\
\hline & $101+$ million & 8 & 9.76 \\
\hline
\end{tabular}

Regarding the tolerance of ambiguity measurement, we used the Tolerance-Intolerance of Ambiguity questionnaire developed by Budner (1962). The questionnaire uses a 16-item scale and it follows a scale ranging from 0 to 100 . A score between 44 and 48 is considered relevantly neutral, while scores below 44 indicate a high tolerance to ambiguity and scores above 48 indicate a low one. Locus of control was examined through the well-known questionnaire developed by Spector (1988). The questionnaire includes 16 semantic different items scored on a 1-6 scale. Regarding the measurement of involvement towards change, we used the McQuarrie and Munson's (1991) revised version of their Revised Personal Involvement Inventory (RPII). 
The questionnaire captures two independent dimensions that evaluate involvement, namely, importance and interest. For the measurement of job satisfaction, we used the 7-item scale Michigan Organizational Assessment Questionnaire developed by Cammann, Fichman, Jenkins, and Klesh (1979), which contains a 3-item overall satisfaction subscale. Finally, for the measurement of organizational commitment, we used Organizational Commitment Questionnaire developed by Mowday et al. (1979) which is composed of 15 semantic different items, scored on a 1-7 scale.

\section{Results}

The descriptive statistical results revealed that the tolerance of ambiguity index value is equal to 59.89. Thus, they reveal CEOs' hesitation towards uncertainty and/or a significant intolerance to the ambiguity that every organizational change involves. Further, their locus of control degree is 3.89 (S.D.: 0.55) on a 1-6 scale. Hence, they consider that the upcoming evolutions depend more on their own behaviors and actions, rather than on luck or chance. Finally, CEOs exhibit significant job satisfaction (mean: 5.26 and S.D.: 1.05, on a 1-7 scale) and also, organizational commitment (mean: 5.35 and S.D.: 1.15, on a 1-7 scale).

The principal component analysis results revealed two factors that constitute hotel CEOs' involvement towards change (see Table 3): (1) importance (variance 38.96\%); and (2) interest (variance 20.12\%). The two factors had eigenvalues greater than 1 and accounted for $59.08 \%$ of the total variance. Further, high reliability characterizes the two factors. The Cronbach coefficient alpha is 0.82 for the importance factor and 0.74 for the interest factor. On the whole, CEOs' involvement dimensions are relevantly positive. The factor of importance, on a 1-6 scale, has a value equaling to 3.22 (S.D.: 1.09) and the factor of interest has a value equaling to 3.31 (S.D.: 1.02).

Table 3

Involvement Factor Analysis Results

\begin{tabular}{lcc}
\hline Question & Importance & Interest \\
\hline DQ1 & 0.798 & \\
DQ3 & 0.778 & \\
DQ6 & 0.761 & 0.812 \\
DQ10 & & 0.754 \\
DQ9 & & 0.688 \\
DQ2 & & 0.672 \\
DQ5 & 3.759 & 2.022 \\
Eigenvalue & 38.96 & 20.12 \\
Variance (\%) & 0.82 & 0.74 \\
Cronbach $\alpha$ & $3.22( \pm 1.09)$ & $3.31( \pm 1.02)$ \\
Mean and S.D. & &
\end{tabular}

Finally, the correlation between the two factors that capture Greek CEOs' involvement towards change ambiguity and uncertainty is in general medium to low degree $(0.430, p<0.01$; see Table 4$)$.

Table 4

Factors' Correlation

\begin{tabular}{lll}
\hline Factor & Importance & Interest \\
\hline Importance & & $0.430^{* * * *}$ \\
Interest & & \\
\hline Note. ${ }^{* * * *}: p<0.01$. & &
\end{tabular}


Ordinary regression was run in order to examine the impact of managers' perceptional, emotional, and cognitive attitudes on their tolerance of ambiguity. Regarding the hypothesis of the paper, we can observe (see Table 5):

H1: Only locus of control, interest, and job satisfaction emerged as significant predictors of CEOs' tolerance of ambiguity.

Table 5

Regression Analysis Results

\begin{tabular}{ll}
\hline Variable & Dependent variable: tolerance of ambiguity \\
\hline (Constant) & $30.73^{* * * *}$ \\
Locus of control & $-3.12^{* * *}$ \\
Importance & -0.812 \\
Interest & $-1.49^{* * *}$ \\
Job satisfaction & $-4.15^{* *}$ \\
Organizational commitment & 0.312 \\
$F$ & $8.24^{* * *}$ \\
$N$ & 82 \\
$R^{2}$ & 0.38 \\
\hline Notes. ${ }^{* * *}: p<0.05 ;{ }^{* * * * *}: p<0.01$. &
\end{tabular}

\section{Discussion and Implications}

The findings reveal relevant CEOs' hesitation towards change and/or intolerance to the ambiguity/uncertainty that every organizational change involves (tolerance of ambiguity $=59.89$ ). However, taking into account the dynamic nature of the Greek tourism industry, we may assume that the interpretation of the results is worsening and ultimately may reveal that CEOs' tolerance of ambiguity is unsatisfactory and disconcerting. We may assume that a possible reason is the Greek national and business culture (norms and values). Hofstede's (2001) research findings suggest that within a sample of 56 nations, Greece has the highest uncertainty avoidance value (Greece: 112; nations' mean average: 66.4). Further, other researches also suggest that low ambiguity tolerance (Nicolaidis \& Katsaros, 2011) and high uncertainty intolerance (Nicolaidis, 1992) characterize the culture of Greek firms in terms of risk evasion and change avoidance.

From the resource-based view of strategic management, this paper suggests three main strategic policies that may influnce effectively CEOs' tolerance of ambiguity. Most importantly, the proposed policies may strengthen hotels' strategy of growth (e.g., the provision of more and new services to the same and new markets, to the diversification of their activities). The three strategic policies refer to: (1) the development of CEOs' internal locus of control; (2) the enhancement of CEOs' interest; and (3) the increase of CEOs' job satisfaction.

Greek hotels' CEOs should try to cultivate their internal locus of control. We suggest that personal control (one of the five core dimensions of empowerment; Whetten \& Cameron, 1995) may facilitate CEOs to increase the internal locus of control by applying a mix of the following three main practices: (1) fostering personal mastery experiences, which helps managers to master experience over challenges, problems, or difficulties; (2) providing resources, which refers to enhancing technical and administrative support to managers; and (3) organizing teams, which refers to enhancing the capabilities of managers who participate in teams because they want to do things beyond their personal abilities (e.g., share information, formulate and choose solutions which they can either implement personally or in cooperation with others). The implementation of the above practices may, in turn, raise CEOs' tolerance of ambiguity. 
Greek hotels should also consider the advantages that they may gain by investing in the increase of their CEOs' interest. This, we argue, could happen through the employment of education/communication management practices (Johnson \& Scholes, 2002) that may advance CEOs' interpersonal relations through the establishment of a favorable supportive organizational climate that may assist them in communicating their ideas more clearly and trustfully (J. A. Fitzsimmons \& M. J. Fitzsimmons, 2006). In addition, Greek hotels should also consider: (1) facilitating CEOs to perceive all the exciting and interesting change aspects, through the use of certain strategic tools (i.e., future search, real-time strategic change, open space processes); and (2) utilizing job involvement practices in order to enhance CEOs' interest towards change ambigutiy and hence, ensuring their support even if it requires further time and effort.

Statistical results also indicate that CEOs' tolerance of ambiguity can be further increased if they manage to empower their job satisfaction in their working environment. Thus, CEOs should try to: (1) take responsibility for the ambiguous aspects of their work; (2) influence their emotions in order to stress the compatibility between important personal values and change variables; and (3) replace negative emotions, such as fear or anxiety, with positive emotions, e.g., excitement, passion, or anticipation that can influence ambiguity and make the work environment more attractive. The latter could happen by actions such as encouraging approval, self-reassuring, requesting for feedback, and fostering informal social activities that build cohesion and encourage friendship (Whetten \& Cameron, 1995).

\section{Conclusion}

The research findings demonstrate a worrying level of tolerance of ambigutiy among Greek hotel CEOs. It therefore suggests three strategic policies that may effectively influence their emotional and cognitive behaviors in times of turbulence and uncertainty. Concluding, this paper reveals that deeper and broader research on CEOs' behaviors towards change ambiguity is needed in the tourism industry.

\section{References}

Armenakis, A. A., Harris, S. G., \& Mossholder, K. W. (1993). Creating readiness for organizational change. Human Relations, 46(6), 681-703.

Begley, T. M., \& Boyd, D. P. (1987). Psychological characteristics associated with performance in entrepreneurial firms and smaller businesses. Journal of Business Venturing, 2(1), 79-93.

Benassi, V. A., Sweeney, P. D., \& Dufour, C. L. (1988). Is there a relation between locus of control orientation and depression? Journal of Abnormal Psychology, 97(3), 357-367.

Budner, S. (1962). Tolerance for ambiguity scale. Journal of Personality, 30(1), 29-50.

Cammann, C., Fichman, M., Jenkins, D., \& Klesh, J. (1979). The Michigan organizational assessment questionnaire. University of Michigan: Ann Arbor.

Ely, C. M. (1989). Tolerance of ambiguity and use of second language learning strategies. Foreign Language Annals, 22(5), 437-445.

Fitzsimmons, J. A., \& Fitzsimmons, M. J. (2006). Service management: Operations, strategy, information technology. New York, N.Y.: McGraw-Hill.

Hofstede, G. (2001). Culture's consequences, comparing values, behaviors, institutions, and organizations across nations. Thousand Oaks, C.A.: Sage Publications.

Johnson, G., \& Scholes, K. (2002). Exploring corporate strategy: Text and case. London: Prentice Hall International.

Jonassen, D. H., \& Grabowski, B. L. (1993). Handbook of individual differences: Learning \& instruction. Hillsdale, N.J.: Lawrence Earlbaum Associates.

Judge, T. A., Thoreson, C. J., Pucik, V., \& Welbourne, T. (1999). Managerial coping with organizational change: A dispositional perspective. Journal of Applied Psychology, 84(1), 107-122. 
Kirton, M. J. (1981). A reanalysis of two scales of tolerance of ambiguity. Journal of Personality Assessment, 45(4), 407-414.

Langton, N., \& Robbins, S. (2006). Organizational behaviour. Toronto: Pearson Prentice Canada.

Lau, C., \& Woodman, R. C. (1995). Understanding organizational change: A schematic perspective. Academy of Management Journal, 38(2), 537-554.

Lauriola, M., \& Levin, I. P. (2001). Relating individual differences in attitude toward ambiguity to risky choices. Journal of Behavioral Decision Making, 14(2), 107-122.

Madsen, S., Miller, D., \& Cameron, J. (2005). Readiness for organizational change: Do organizational commitment and social relationships in the workplace make a difference? Human Resource Development Quarterly, 16(2), 213-234.

Mamlin, N., Harris, K. R., \& Case, L. P. (2001). A methodological analysis of research on locus of control and learning disabilities: Rethinking a common assumption. Journal of Special Education, 34(4), 214-225.

McQuarrie, E. F., \& Munson, J. M. (1991). A revised product involvement inventory: Improved usability and validity. In J. F. Sherry, \& B. Sternthal (Eds.), Advances in consumer research (pp. 108-115). Provo, U.T.: The Association for Consumer Research.

Mowday, R., Steers, R., \& Porter, L. (1979). The measurement of organizational commitment. Journal of Vocational Behavior, 14(2), 224-247.

Nicolaidis, C. S. (1992). Cultural determinants of corporate excellence in an integrated world economy: The impact of national cultures on organizational performance. In M. C. Casson (Ed.), International business and global integration: Some empirical studies. London: MacMillan.

Nicolaidis, C. S., \& Katsaros, K. (2011). Tolerance of ambiguity and emotional attitudes in a changing business environment: A case of Greek IT CEOs. Journal of Strategy and Management, 4(1), 44-61.

Rotter, J. B. (1975). Some problems and misconceptions related to the construct of internal versus external control of reinforcement. Journal of Consulting and Clinical Psychology, 43(1), 56-67.

Schweiger, D. M., \& DeNisi, A. S. (1991). Communication with employees following a merger: A longitudinal field experiment. Academy of Management Journal, 34(1), 110-135.

Spector, P. E. (1988). Development of the work locus of control scale. Journal of Occupational Psychology, 61(4), 335-340.

Tegano, D. W. (1990). Relationship of tolerance of ambiguity and playfulness to creativity. Psychological Reports, 66(3), 1047-1056.

Wanberg, C. R., \& Banas, J. T. (2000). Predictors and outcomes of openness to changes in a reorganizing workplace. Journal of Applied Psychology, 85(1), 132-142.

Whetten, D., \& Cameron, K. (1995). Developing management skills. New York, N.Y.: HarperCollins College Publishers.

Wilkinson, D. (2006). The ambiguity advantage: What great leaders are great at? London: Macmillan.

Wong, C. S., Hui, C., \& Law, K. S. (1998). A longitudinal study of the job perception-job satisfaction relationship: A test of the three alternative specifications. Journal of Occupational and Organizational Psychology, 71(2), 127-146.

Zimbardo, P. G. (1985). Psychology and life. Glenview, I.L.: Scott Foreman and Company. 